\title{
A Covid-19 chegou no Brasil, e daí? \\ A primeira resposta das redes solidárias sob a perspectiva da dádiva
}

Siegrid Guillaumon (https://orcid.org/0000-0003-2519-9805)' Departamento de Administração, Universidade de Brasília (UnB), Brasília, DF, Brasil. Eloisa Gonçalves da Silva Torlig (https://orcid.org/0000-0003-2519-9805)" Departamento de Administração, Universidade de Brasília (UnB), Brasília, DF, Brasil. Caroline Cordova Bicudo da Costa(https://orcid.org/0000-0003-3251-0059)"I Departamento de Administração, Universidade de Brasília (UnB), Brasília, DF, Brasil.

Fagner de Oliveira Dias(https://orcid.org/0000-0003-2519-9805) IV $^{\mathrm{V}}$ Departamento de Administração, Universidade de Brasília (UnB), Brasília, DF, Brasil. Andréia Elizabeth Silva Barros(https://orcid.org/0000-0002-7409-0550)v Departamento de Administração, Universidade de Brasília (UnB), Brasília, DF, Brasil.

Resumo: 0 artigo apresenta as ações solidárias como primeira resposta à crise Covid-19 no Brasil. Realizou-se uma busca de notícias sobre a formação de redes de solidariedade frente à situação pandêmica no país e realizada uma análise de clusters, em discussão baseada na Teoria da Dádiva. Foram identificados três grupos: cluster de ações de mitigação; cluster integrativo; e cluster de ajuda nos processos. A primeira resposta configura-se em rápida mobilização da sociedade civil para doar produtos e serviços de maneira a complementar às lacunas deixadas pelo Estado por meio de processos semelhantes aos da dádiva. Vislumbra-se uma agenda de atuação para a administração pública nos eixos: legitimidade e reconhecimento para as redes solidárias; fomento da parceria público-privada; e investimento para a ciência e tecnologia. Dentre as lições que podem ser aprendidas estão a dádiva, a cooperação e o compromisso mútuo, bem como as possibilidades para uma gestão pública efetiva e uma sociedade solidária e democrática.

Palavras-chave: Redes de solidariedade. Covid-19. Teoria da Dádiva. Administração pública. Cluster.

\section{Solidarity networks in the covid-19 crisis: from gift theory to implications for public administration}

Abstract: The paper aims to discuss the importance of understanding solidarity networks to increase the effectiveness of public management. A search was conducted to identify published news about the formation of solidarity networks to face Covid-19 pandemic in the country. Afterwards a cluster analysis was carried out in a discussion based on the Gift Theory. Three groups were identified: cluster of mitigation actions; integrative cluster; and a process assistance cluster.
Recebido: 25.06.20 Aprovado: 27.10 .20

\author{
I. Siegrid Guillaumon \\ é professor do \\ Departamento de \\ Administração na \\ Universidade de \\ Brasília (UnB). \\ <siegrid@unb.brm>. \\ II. Eloisa Gonçalves \\ da Silva Torlig é \\ doutoranda em \\ administração \\ no Programa de \\ Pós-Graduação \\ em Administração \\ da Universidade \\ de Brasília (UnB). \\ <eloisatorlig@gmail. \\ com>.
}

III. Caroline Cordova Bicudo da Costa é doutoranda em administração no Programa de Pós-Graduação em Administração da Universidade de Brasília (UnB). <carolinecordova@ live.com>.

IV. Fagner de Oliveira Dias é doutorando em administração no Programa de Pós-Graduação em Administração da Universidade de Brasília (UnB). $<$ fagner.pmdf@gmail. com>.

V. Andréia Elizabeth Silva Barros é mestranda em administração no Programa de Pós-Graduação em Administração da Universidade de 
Brasília (UnB). <andreiabarros@ gmail.com>.

1. O setor público é nominado o primeiro setor, o setor privado o segundo, o terceiro setor se configura em contraste aos dois primeiros, e veio se institucionalizando desde a década de 1970 ao incluir um conjunto de agentes diversos que, por meio de valores societários, promovem atividades públicas originais ou compensatórias. Exemplos desses atores são: entidades de classe, associações, fundações privadas, instituições filantrópicas, movimentos sociais organizados, ONGs e outras organizações assistenciais ou caritativas da sociedade civil (Tenório, 1999: 85).

2. Fórum Social Mundial é um evento de encontro e debate, uma atividade contínua de engajamento que reúne movimentos sociais, terceiro setor, associações para discutir e criar formas alternativas ao paradigma socioeconômico hegemônico neoliberal. Tem como lema: "Um outro mundo é possível" (FSM, 2016).
From the analysis carried out, it is possible to envision an action agenda for the Public Administration in the areas: legitimacy and recognition for solidarity networks; promotion of public-private partnership; and investment in science and technology. An articulated governmental action capable of coordinating the efforts of social actors is expected, which can represent ease, speed and effectiveness in several public policies.

Keywords: Solidarity networks. Covid-19. Gift theory. Public administration. Cluster.

\section{Introdução}

A Organização Mundial da Saúde (OMS), em 11 de março de 2020, declarou a pandemia do novo coronavírus (Covid-19). A crise, por um lado, revela a força das desigualdades de gênero, raça e classe (Silva et alii, 2020), por outro, envolve desafios complexos em todas as áreas de políticas públicas e uma capacidade de mobilização, articulação e coordenação entre diversos atores, em curto e médio prazo, sem precedentes (Schmidt, Mello \& Cavalcante, 2020).

Em meio aos graves impactos sociais e econômicos da pandemia, que atingiram particularmente populações em vulnerabilidade (Silva et alii, 2020), observou-se o surgimento de iniciativas de diversos setores para mitigar os efeitos desses impactos, tendo em vista que o Estado brasileiro é ineficiente para equacionar urgentes problemas sociais, gerando um vácuo de ações que passa a ser ocupado por outros atores sociais e diferentes iniciativas associativas. De maneira ampla, isto é denominado terceiro setor ${ }^{1}$ (Fischer, 1998), no qual se reconhece uma diversidade de iniciativas e articulações, bem como formas organizativas inovadoras.

O Fórum Social Mundial² (FSM) já revelava as características centrais das formas organizacionais que a sociedade civil desenvolve para minimizar ou mitigar processos de desigualdade: a natureza em rede com a presença da solidariedade. Para o FSM esse fenômeno organizacional se traduz como redes solidárias. De maneira mais ampla, as redes de solidariedade estão pautadas na questão de como indivíduos e grupos socialmente conscientes podem se reunir em torno de uma ampla solidariedade pautada em valores de antiopressão para conquistar mudanças sociais, sociopolíticas e socioeconômicas para o futuro (FSM, 2016). Dagnino (1994: 107) traz ideias mais amplas dos movimentos sociais como redes semelhantes nas quais os sujeitos são coletivos, múltiplos, heterogêneos e compartilham princípios básicos sobre participação popular, cidadania e construção democrática por meio da cogestão de serviços públicos.

Waterman (2004) identifica a característica de um "movimento de movimentos" nas redes de solidariedade, podendo mudar de forma, tamanho, capacidade de ação e objetivos. As redes solidárias seriam ainda caracterizadas pela velocidade 
de comunicação, flexibilidade e adaptabilidade estrutural. O elemento de solidariedade presente nessas redes não seria estático, ideal, mas concebido por meio de um processo continuado de adaptação (Waterman, 2004; Smith, 2009). Redes solidárias agem como mecanismos de alívio emergencial para grupos em necessidade e existem tendências de aumento de participação pública para legitimar redes de voluntariado informal (Georgeou \& Haas, 2019) ou redes solidárias locais no nível das vizinhanças e comunidades (Clarke, 2015; Wei \& Marinova, 2016).

As redes de solidariedade estabelecem laços fortes entre seus membros, que, no entanto, podem ser curtos e intensos. A diversidade é uma característica relevante da rede de solidariedade, não apenas aceita, mas fundamental, já que o capital social da rede reside justamente na diversidade de informações, fontes de recursos, e oportunidades criadas pelo estabelecimento de uma conexão que falta entre grupos sociais desiguais (Smith, 2009). Ainda segundo Smith, as redes de solidariedade são um veículo que permite a diferentes entidades unirem esforços para realizar ações de interesse público e, simultaneamente, na consecução de interesses próprios. Oferecem oportunidades para que os grupos se conectem e fortaleçam laços locais e globais.

A solidariedade, portanto, pode ser descrita como uma intermediação entre grupos sociais distintos mobilizados por um interesse comum (Gargiulo \& Benassi, 2000; Smith, 2009). As redes solidárias são colaborativas e não competitivas, baseadas na solidariedade e cooperação, e não na busca da satisfação de interesses próprios (Guadalupe \& Cardoso, 2018). Os objetivos das redes solidárias transcendem os objetivos dos membros individuais da rede. A unidade coletiva formada por meio de vínculos pessoais é o que mais importa nas redes solidárias (Breiger \& Roberts, 2012). A motivação é inspirada pela mutualidade e reciprocidade, não necessariamente altruísta, mas envolve a crença em um conjunto de princípios de apoio mútuo e objetivos a serem alcançados por meio de colaboração (Smith, 2009), de modo que o objetivo comum seja de atender às necessidades dos membros de uma comunidade sem focar prioritariamente no retorno de capital (Neamtan, 2002; Wei \& Marinova, 2016; McGoey, 2018).

Para ampliar a compreensão das redes solidárias, foi realizada uma exploração na base de dados Scopus visando identificar a produção de trabalhos na temática abarcada e verificar como pode apontar novos caminhos para reflexão. Ao utilizar os critérios de busca "social" and "network" and "solidarity" or "solidaire", sem recorte temporal, e excluindo-se todos os trabalhos realizados no campo do conhecimento da medicina, a busca retornou 1.007 resultados. Realizou-se a extração dos trabalhos para análise de repetição de palavras no software VosViewer, que 
FIGURA 1

REDE DE PALAVRAS-CHAVE DOS ARTIGOS ENCONTRADOS COM TERMOS DE BUSCA: REDES SOCIAIS E SOLIDARIEDADE, EM PERSPECTIVA DE AGLOMERAÇÕES

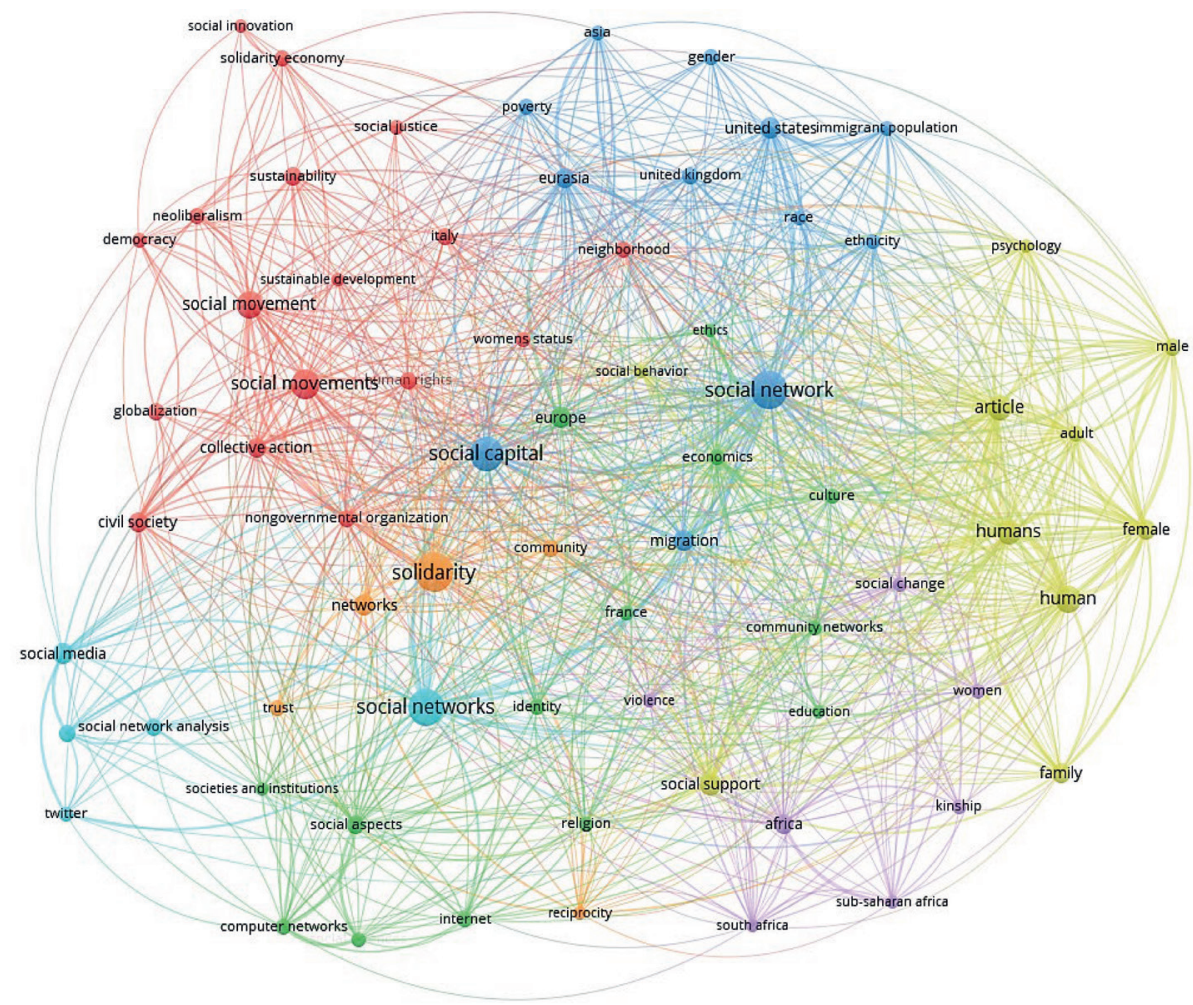

Fonte: Elaborada pelos autores com uso do software Vosviewer.

estabelece a rede de palavras-chave entre os estudos extraídos, levando à Figura 1 que considera as 70 palavras que se repetem no mínimo 11 vezes no universo de artigos extraídos da base Scopus com um total de 4.110 palavras-chave.

Fica evidente que estudos sobre redes sociais e solidariedade mobilizam conceitos como capital social (rede em azul) e movimentos sociais (rede em vermelho), estando mais amplamente desenvolvidos sob estes conceitos, já que são as maiores esferas com o maior número de repetições. Já os aspectos computacionais das redes sociais (em verde) os aspectos humanos e de gênero (em ocre) os estudos territoriais e de imigração (violeta) e de solidariedade, reciprocidade, comunidade e confiança (laranja) são menos expressivos, ou seja, são temáticas correlacionadas ainda menos exploradas, e que, portanto, configuram maiores lacunas de conhecimento, sendo que esta última desperta o interesse deste estudo.

Ao observar os conceitos de reciprocidade, solidariedade, movimentos sociais, sus- 
FIGURA 2

REDE de PALAVRAS-CHAVE dos ARTIGOS ENCONTRAdOS COM TERMOS DE BUSCA: REDES SOCIAIS E SOLIDARIEDADE, EM PERSPECTIVA TEMPORAL

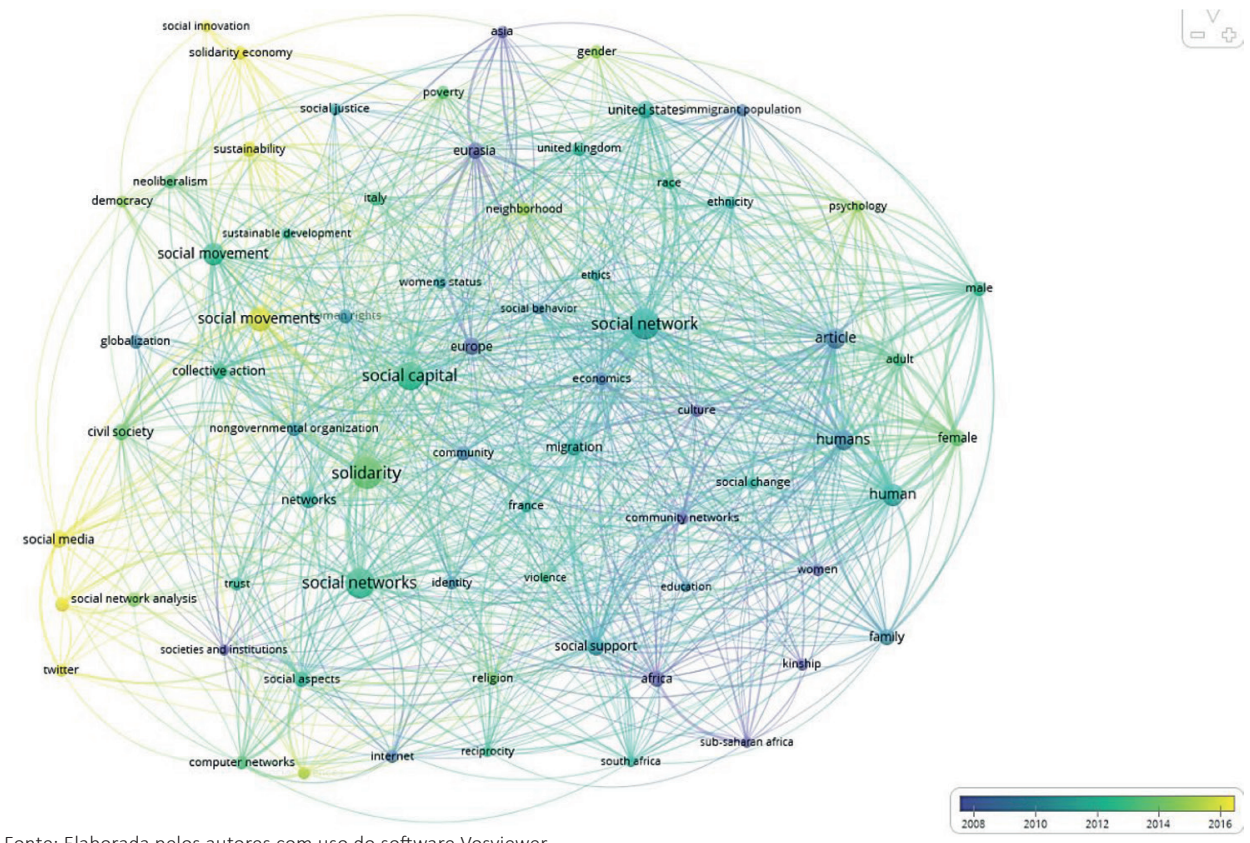

Fonte: Elaborada pelos autores com uso do software Vosviewer.

tentabilidade e economia solidária na mesma rede de palavras organizada desta vez por ano de publicação (Figura 2), verifica-se em amarelo os conceitos mais recentes no desenvolvimento dos estudos sobre redes sociais e solidariedade, reforçando a necessidade de mais estudos nessas vertentes. E ao considerar ainda que a solidariedade é um dos valores que pode fundamentar o interesse público, o bem público, existindo uma ética de responsabilidade social nas redes de solidariedade, vinculadas à pluralidade e empoderamento para a obtenção de um mundo mais justo, sustentável e democrático (Tackacs, Janky \& Flache, 2007), a pergunta de pesquisa é delineada a seguir: Como se configuraram as ações solidárias no período de primeira resposta à crise Covid-19 no Brasil? Ressalta-se que o período de primeira resposta delimitado neste estudo se situa entre 26 de fevereiro a 5 de abril de 2020.

\section{Solidariedade e Teoria da dádiva}

O conceito contemporâneo de solidariedade evoca duas perspectivas opostas (Laville, 2009: 310). Na primeira, a solidariedade é descrita como ação filantrópica, voluntária e altruísta. É um meio de alívio imediato das populações pobres, e está fundamentada na ajuda que aqueles que mais têm dividem com os menos favorecidos - a

3. Caillé (2002) adverte que esta é a lógica econômica que rege algumas empresas do mercado, na qual o aparente altruísmo esconde uma dimensão de utilitarismo nestas ações. Existem ainda ações voluntárias coletivas gratuitas em que a relação entre os atores não se baseia na lógica econômica (Melucci, 2001). 


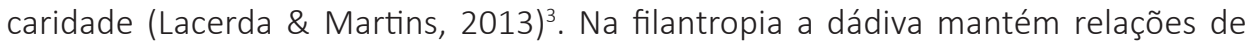
hierarquia e o poder maior é dos doadores, já que aqueles que recebem a doação não têm como retribuir, restando como única alternativa a gratidão (Laville, 2009). Nessa perspectiva, a solidariedade mantém vínculos de dependência que impedem autonomia (Lacerda \& Martins, 2013). Na segunda perspectiva, a solidariedade é democrática e pautada na reciprocidade dos atores ao traduzir participação social, engajamento de sujeitos para a transformação social, recorrendo à autonomia e a preservação da liberdade e de direitos igualitários. É nessa visão que encontramos o apoio social como elemento estruturante da solidariedade, baseado na ajuda mútua e na expressão reivindicativa que mobilizam o movimento social e a auto-organização (Laville, 2009: 310). Esse tipo de solidariedade visa o fortalecimento da esfera pública como agente de transformação (Laville, 2009; Lacerda \& Martins, 2013).

Alguns campos do conhecimento abarcam o conceito de redes de solidariedade, como a economia social (Mullan \& Cox, 2000) e a economia solidária (Laville, 2009). Os movimentos denominados antiautoritários seriam característicos de uma sociedade pós-industrial pós-materialista, cujas bases residem na modificação de relações usuais de produção e consumo para bases mais solidárias, com a responsabilização de membros organizados em unidades econômicas geridas coletivamente, ainda que inseridas em uma lógica de mercado (De Certeau 1980 apud Laville, 2009, McGoey, 2018). O que se observa, a partir dessas perspectivas, são fundamentos da ação coletiva organizadas em formatos associativos e em redes de alianças nas quais os valores do vínculo social não exclusivamente utilitários estão ancorados no sentimento de pertencimento a uma rede (Brito, 2007) em que os vínculos são mais importantes do que o valor das trocas na rede.

Tal conjunto de ideias remete à sociologia da dádiva. Formulada inicialmente por Marcel Mauss em seu Ensaio sobre a dádiva, de 1925 (Mauss, 2003; Martins, 2005; Rigo \& França Filho, 2016), retrata uma relação circular em que o dar, o receber e o retribuir é entendido como um movimento permanentemente recriado nos grupos sociais em rede. A sociologia da dádiva tem como principal fundamento o fenômeno da dádiva, identificado por Mauss como um fato social total que se forma a partir do conjunto de enclaves sociais (econômico, político, jurídico, afetivo, estético etc.), mas também porque é uma prática universalmente desenvolvida que pode ser reconhecida em todas as sociedades, em diferentes matizes e graus (Godelier, 2001; Caillé, 1998 apud Vizeu, 2009, Rigo \& França Filho, 2016). Mauss reconheceu na dádiva o fundamento limítrofe para identificar a essência das motivações individuais que levam à solidariedade humana e que, dessa forma, explicam a dinâmica social.

Em sua obra, busca explicar as origens da troca, o que o leva a descobrir sociedades 
de reciprocidade, nas quais a dádiva e a contradádiva pertencem ao que denominou dialética social econômica. Na dinâmica da dádiva, para poder dar é preciso produzir, o que significa que a produção está subordinada à doação, gerando uma economia com princípios inversos àqueles das trocas que embasam a economia ocidental. Para Mauss (2003), a dádiva é o oposto da troca mercantil: aponta a essência da reciprocidade evidenciando o ciclo de dar-receber-retribuir (Martins, 2005; Brito, 2007). A dádiva é descrita como forma de circulação de bens cujo objetivo é criar ou fortalecer os vínculos entre pessoas e grupos. Para tanto, a dádiva deve ser empreendida sem a garantia de retorno (Caillé, 2002). Em oposição à troca mercantil, a troca-dádiva associa-se a uma moral, um valor ético na transação econômica (Mauss, 2003: 299; Sabourin, 2004; Vizeu, 2009).

A troca-dádiva não se restringe às trocas de bens e riquezas, mas se trocam amabilidades, ritos, serviços militares, festas. Equivale a um crescimento da consciência de ser, de pertencer (Mauss, 2003: 212). O prestígio do doador nasce da dádiva e cria-se uma dependência: aquele que recebe se sente simbolicamente obrigado a restituir o que recebeu, nem sempre para a mesma pessoa. Mauss (2003) conclui que as dádivas vão e voltam sempre, em um ciclo, não importando seu valor ou natureza de troca-dádiva. A reciprocidade implicada na dádiva se traduz em uma preocupação com o outro, com suas condições de existência. Essa preocupação com o outro são os motivos e as obrigações para a produção material e de valores afetivos ou éticos, como a paz, a confiança, a amizade e a compreensão mútua (Sabourin, 2004).

A reciprocidade não está limitada à dádiva entre pares, regendo também relações entre grupos. Pode ser uma reciprocidade direta quando ocorre entre os mesmos grupos; ou indireta, quando os bens materiais ou simbólicos não são devolvidos a quem os deu, mas a outros grupos, que, por sua vez, devolverão a novos grupos. A reciprocidade que Mauss (2003) caracterizou como indireta é típica da circulação dos bens através de gerações. Incluem-se aí as dádivas da educação, da cultura e do meio ambiente. Os indivíduos que agem por meio da moral da dádiva têm um senso agudo de si mesmo, dos outros e da realidade social, tendo como objetivo ético e político não apenas a garantia de suas condições materiais, mas das condições de vida para todos os seres humanos como forma de pertencimento individualizado e diferenciado em uma totalidade humana (Sabourin, 2008).

Apesar de a dádiva ter sido inferida a partir da observação de sociedades originárias polinésias, a moral e economia descritas a partir desta visão estão presentes em todas as sociedades. Na sociedade moderna, que tem a troca mercantil como um de seus pilares, tende-se a pensar todas as relações humanas são dessa forma, 
o que não significa que a dádiva seja uma prática incomum, mas que há uma tendência a desconsiderar os pressupostos da troca-dádiva centradas no vínculo, pois a lógica mercantil exerce mais influência (Vizeu, 2009: 415). Trata-se de um fundamento social que antecipou muitas das questões humanas contemporâneas - é um princípio universal. O sistema de previdência social, por exemplo, em todo o mundo é pautado no princípio de que o trabalhador dá sua vida e seu trabalho a um patrão e a uma coletividade, mas não serão essas mesmas pessoas que garantirão sua seguridade quando do desemprego, da velhice e da morte (Mauss, 2003).

Outra dinâmica da dádiva é identificada nas redes de colaboração em massa e desenvolvimento de software livre, quando indivíduos trabalham em favor da criação de um conhecimento comum, sem esperar reciprocidade direta dos usuários dos sistemas desenvolvidos, mas se beneficiando em algum momento de outras informações aportadas por outros indivíduos não necessariamente os mesmos que consumiram o bem coletivo (Aguiar, 2007). A teoria da dádiva tem sido mobilizada ainda para explicar dinâmicas de gestão em empresas familiares, visto que o lócus mais evidente da dádiva é a família (Gadelha, 2007).

No campo da gestão pública, a teoria da dádiva já foi mobilizada para fortalecer diversos argumentos como: ser base para uma reforma moral do Estado (Martins, 2004); a economia solidária como nova forma de gestão pública (França Filho, 2013); fundamentar a gestão de unidades públicas de conservação (Burkowski \& Boas, 2013); dádiva e políticas de reparação (Mallard, 2011); para a construção de políticas públicas (Gonçalves, 2010).

Em que pese a importância da dádiva como mecanismo de mobilização social pleno, ela oferece ainda potencial para a definição de uma nova gestão pública e construção democrática. Dagnino (2004) aponta críticas relevantes quanto ao entendimento da relação do Estado com movimentos sociais como os caracterizados pela dádiva. Há o argumento de que a construção democrática não avança devido à "confluência perversa entre dois processos políticos distintos" (Dagnino, 2004: 97). Por um lado, o alargamento da democracia por meio da ampliação de espaços de participação da sociedade civil e, por outro, a existência de um projeto intencional de Estado mínimo que o isenta progressivamente de seu papel de Estado garantidor de direitos, encolhendo suas responsabilidades sociais transferindo-as para a sociedade civil (Dagnino, 2004: 95-96). A perversidade residiria no fato de que ambos os processos políticos exigem uma sociedade civil engajada, ativa e propositiva, embora os resultados de sua ação a longo prazo sejam antagônicos.

Experiências da sociedade civil atuando ao lado do Estado nos processos de to- 
mada de decisão (processos participativos), e apostando nos resultados democratizantes destas ações, acabam servindo aos objetivos contrários de transferência das responsabilidades do Estado para a sociedade civil reduzindo sua obrigação de garantia de direitos. A perversidade se acentua ainda mais quando movimentos sociais entendidos como parceiros ideais do Estado (devido à sua competência técnica e inserção social e interlocução confiável) eventualmente recusam o papel de transferência de responsabilidades e, consequentemente, percebem que seus resultados se tornam pontuais, limitados, provisórios e fragmentados com relação à redução da desigualdade e melhoria das condições de vida (Dagnino, 2004: 101)4

A declaração da crise pandêmica no Brasil, em março de 2020, parece ter recriado um contexto para ampliação da consciência individual de pertencimento a um grupo social maior, no qual as condições de existência dos diversos segmentos sociais passam a importar mais, ensejando assim a necessidade de retomar e fortalecer vínculos sociais (como contraponto ao individualismo consumista mercantil) para travessia coletiva da pandemia. Nesses aspectos é que se pretende verificar como se configuraram as ações solidárias no período de primeira resposta à crise Covid-19 no Brasil.

\section{Percurso metodológico}

Para atingir o objetivo proposto, foi conduzido um estudo qualitativo que se classifica como exploratório e descritivo. Optou-se pela pesquisa documental, realizada por meio de uma coleta de dados a documentos secundários que ocorreu na plataforma digital do Google Notícias ${ }^{5}$, utilizando a navegação anônima. A pesquisa documental permite o estudo de fatos para os quais não se tem acesso físico, além de os documentos se referirem a fontes de informação não reativa, permanecendo inalterados mesmo em longos períodos (Godoy, 1995). Logo, essa opção se mostrou apropriada ao objetivo do presente estudo. A escolha da base de dados, por sua vez, foi motivada por centralizar notícias de distintos websites, permitindo o acesso a informações que contemplam diferentes regiões do Brasil.

As palavras-chave que guiaram as buscas foram "rede de solidariedade" e "Covid-19", considerando o período de 26 de fevereiro a 5 de abril de 2020. O interesse no recorte temporal apontado foi o de analisar a resposta de organizações e sociedade civil frente à situação de pandemia no país em termos atuação solidária, considerando os primeiros 40 dias após a confirmação do primeiro caso da doença pelo Ministério da Saúde. O interesse foi analisar a forma como aconteceu a primeira resposta à pandemia de Covid-19, em termos de ações e atitudes solidárias, focando no estágio mais embrionário do fenômeno, antes mesmo que meios ins-
4. Esta dinâmica perversa é descrita como especificidade dos países sulamericanos, devido à sua trajetória histórica e institucional (Dagnino, 1994; Dagnino, 2004; Dagnino, Olvera \& Panfichi, 2006).

5. Disponível em: $<$ https://news. google.com/>. 
titucionais e centralizadores de doações e informações fossem disponibilizados. Como critério inicial para seleção de notícias que iriam compor o estudo, foi considerada necessária menção a, pelo menos, uma rede de solidariedade no contexto da notícia. Salienta-se que esse critério considerou o termo "rede de solidariedade" a partir da perspectiva ampla de veiculação em mídia digitais e pela sociedade civil para representar ações ou atitudes solidárias. Foge do escopo da pesquisa avaliar se a utilização do termo "rede" cumpria requisitos teóricos para se enquadrar como tal. Em consideração à ampla utilização do termo durante o período inicial da pandemia, se optou por manter a nomenclatura como utilizada em sua forma original.

Inicialmente, foram retornadas 121 notícias, dentre as quais 33 foram rejeitadas na checagem do título e resumo, visto que eram de caráter informativo, relato pessoal, repetidas ou referentes a outros países. Nessa fase ocorreu o primeiro processo de filtragem, como mencionado. Entre as 88 notícias restantes, cinco foram desconsideradas por limitação de acesso apenas para assinantes, 14 por abordarem ações isoladas ou campanhas publicitárias e uma por desativação do website. Assim, 68 notícias foram consideradas aptas ao estudo, possibilitando a identificação de 80 "redes de solidariedade" (Quadro 1).

Foram, ainda, verificadas quatro informações possíveis de serem checadas em todas essas 80 redes de solidariedade, quais sejam: ações da rede, atores envolvidos, região de atuação e fatores mobilizadores. A Figura 3 apresenta as escolhas e processos de filtragem utilizados na coleta de dados. Após a finalização da coleta de dados, foi utilizada a técnica de análise de agrupamento, visando classificar objetos conforme critério de semelhança a partir de um conjunto de características (Hair et alii, 2009).

O método de agrupamento adotado foi o Two-Step, por possibilitar a análise escalonável de dados, a partir de variáveis contínuas e/ou categóricas. Foram definidas quatro variáveis de entrada, quais sejam: Iniciativa, contendo o setor do qual partiu a ideia da rede; Ajuda, contendo o tipo de ajuda prestada; Região, contendo a região do Brasil em que foi feita a ação; e Multisetorial, indicando se a ação partiu de um ou mais setores. O agrupamento pela técnica Two-Step iniciou-se com a formação de "pré-clusters", o que possibilitou a redução do tamanho da matriz e, em seguida, os clusters foram formados a partir do critério de distância (Cohrs et alii, 2013). Os resultados apontaram uma distribuição satisfatória dos dados referentes às 80 redes de solidariedade, que foram organizadas em três grupos, ou clusters.

Finalmente, foi realizada uma análise qualitativa a partir do conteúdo de trechos de fala de participantes das redes, sempre que destacados nas notícias. Foram uti- 
QUADRO 1

REDES DE SOlIDARIEDADE CONSIDERAdAS NO ESTUdO

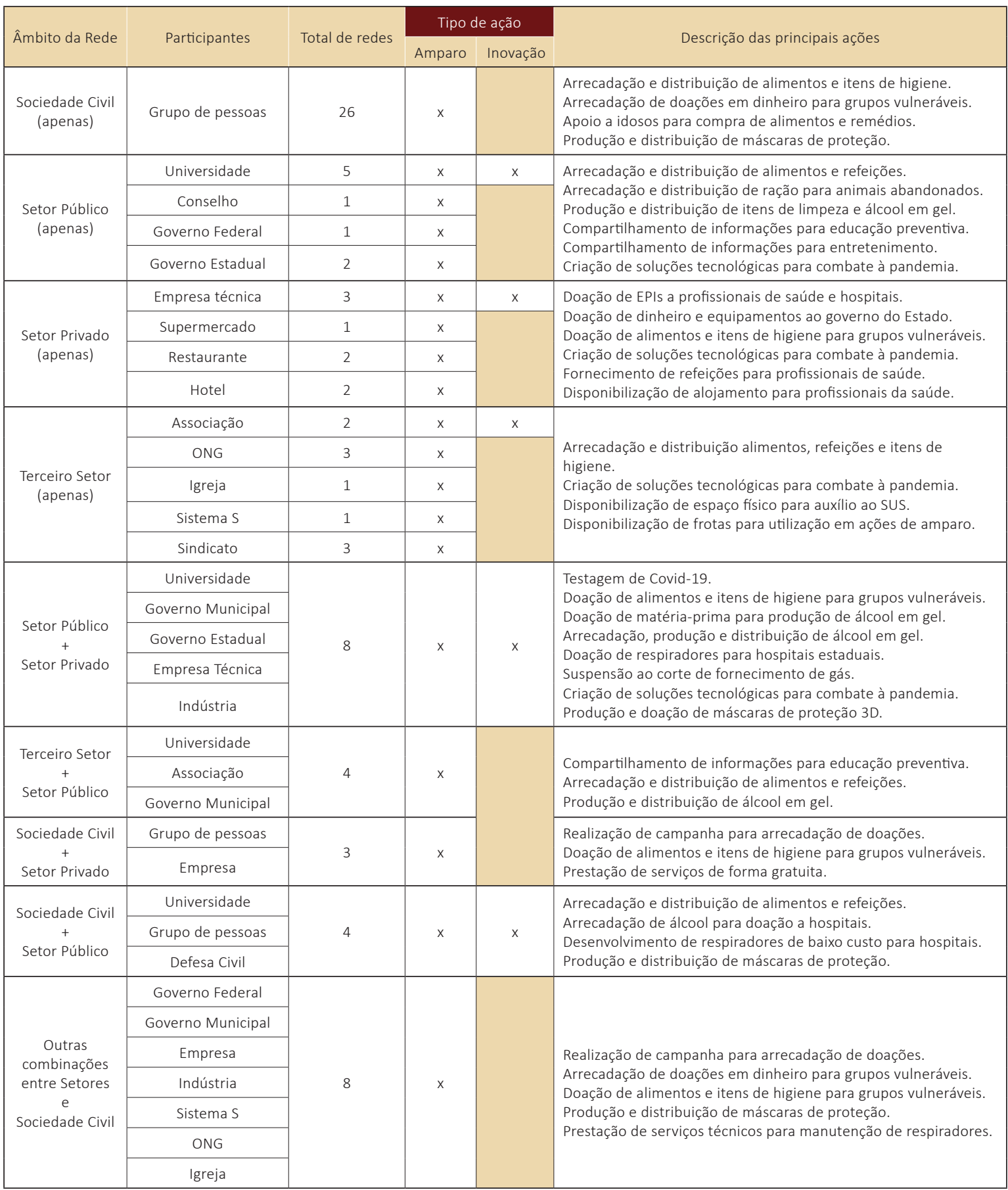

Fonte: elaborada pelos autores. 
FIGURA 3

ESCOLHAS E PROCESSO DE FILTRAGEM

$\mathbf{1}^{\circ}$
$\begin{gathered}\text { Coleta de dados na plataforma Google Notícias com as } \\ \text { palavras-chave "rede de solidariedade" e "covid-19" } \\ (\mathrm{n}=121) .\end{gathered}$

$2^{\circ}$

Exclusão baseada nos critérios de aderência ao escopo do estudo por meio da leitura de título, resumo da notícia e menção à rede $(n=88)$.
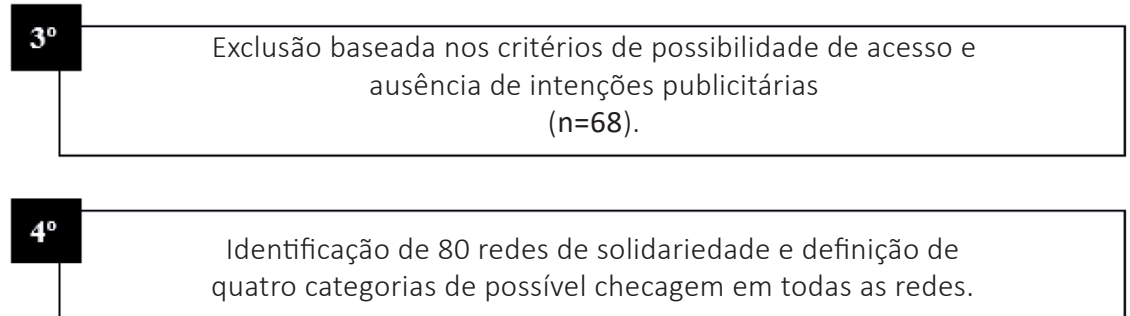

Fonte: Elaborada pelos autores (dados da pesquisa)

lizadas técnicas sugeridas por Flick (2013), iniciando com um resumo do conteúdo das falas, seguido pelo agrupamento de trechos similares e de uma análise explicativa para esclarecer as mensagens dos sujeitos. Assim, foi observada aproximação dos fatores mobilizadores relatados pelos participantes das redes aos conceitos e definições da Teoria da dádiva (Mauss, 2003), base teórica utilizada no presente estudo.

\section{RESULTADOS E DISCUSSÃO}

Na Figura 4, as quatro variáveis estão representadas por um gráfico de colunas em que a barra representa a porcentagem de cada característica do grupo formado, em relação a barra mais opaca ao fundo. A intensidade da cor ao fundo das variáveis descreve a importância desta variável para a separação dos clusters. Ao analisar a distribuição das características, os grupos foram intitulados como segue.

Cluster de ações de mitigação. São caracterizados por ações em que predominaram as redes de solidariedade que objetivaram amenizar e/ou mitigar os efeitos iniciais da pandemia, normalmente ações de curto prazo e de efeito imediato. A iniciativa das ações desse tipo comportam 80,8\% das ações iniciadas pela sociedade civil não organizada, isto é, iniciativas de bairro, amigos e autônomos que decidiram fazer 
diversas ações on-line como dar aulas, apresentações teatrais, consultas psicológicas, médicas e, exclusivamente nesse cluster, ações de apoio a idosos para evitar que eles precisem sair às ruas. $60 \%$ das iniciativas da sociedade civil organizada também estão nesse grupo, principalmente representados por ONGs, sindicatos e associações que fizeram campanhas de doações de alimentos, higiene e todo tipo de material para amenizar os efeitos imediatos do isolamento para os grupos mais vulneráveis. Essas ações representam $62 \%$ das ações que não envolveram outro setor e somente $3 \%$ foram realizadas em conjunto. Quanto à região dessas ações, 60\% ocorreram em todo o Brasil devido às ações on-line que não se delimitam por região, 57,9\% das ações no Sudeste e $50 \%$ das ações no Centro-Oeste. Dentre as ações na Região Sul somente 9,1\% foram do tipo de mitigação.

Cluster integrativo. São caracterizados por ações que envolvem mais de um setor e normalmente iniciado pelo setor público que solicita apoio de outros setores em suas ações. O cluster integrativo é composto por $83,3 \%$ das ações iniciadas pelo setor público, $40 \%$ da sociedade civil organizada, $20 \%$ do setor privado e $19,2 \%$ da sociedade civil não organizada. A denominação de cluster integrativo se deve ao fato de que $81,8 \%$ das ações multissetoriais estão nesse grupo. Suas ações são variadas em tipo de ajuda. Neste grupo, $60 \%$ das ações são de amparo ao trabalhador, $60 \%$ de inovação e serviços, $50 \%$ de informação e cuidado, $43,5 \%$ de produtos de linha de frente, $25 \%$ de serviços on-line e $22,6 \%$ de doações de alimento e higiene. Representa 72,7 \% das ações da Região Sul e 40\% das ações da Região Norte, locais com mais ações desse tipo. Destacaram-se ações de manutenção do emprego ou de ajuda para desempregados, coleta de materiais para a produção de equipamentos de proteção, ações para produção de material de proteção individual para hospitais, bombeiros e policiais, assistências diversas dos setores do governo, ações de prefeituras em conjunto com o setor privado e sociedade para arrecadação de cobertores, comida e álcool em gel. Ações integrativas com iniciativa do governo aconteceram principalmente na Região Sul do país ${ }^{6}$.

Cluster de ajuda nos processos. São caracterizados por ações que procuraram apoiar os processos de combate à pandemia, ou seja, oferecer estrutura para trabalhadores da linha de frente, materiais de proteção e higiene, transporte, doação de respiradores entre outros. É composto por $100 \%$ das ações iniciadas pelas universidades públicas, $80 \%$ das ações iniciadas pelo setor privado e apenas 5,6\% das ações do setor
6. Aparentemente a Região Sul apresenta características (talvez institucionais ou culturais) em que há participação ativa da comunidade nas ações públicas, haja vista ser pioneira na implementação do orçamento participativo, com os conselhos comunitários atuando como nova instância política, o poder comunitário. Para saber mais, consultar James Giacomoni (2010). 
FIGURA 4

ANÁLISE DE CLUSTER TWO-STEP

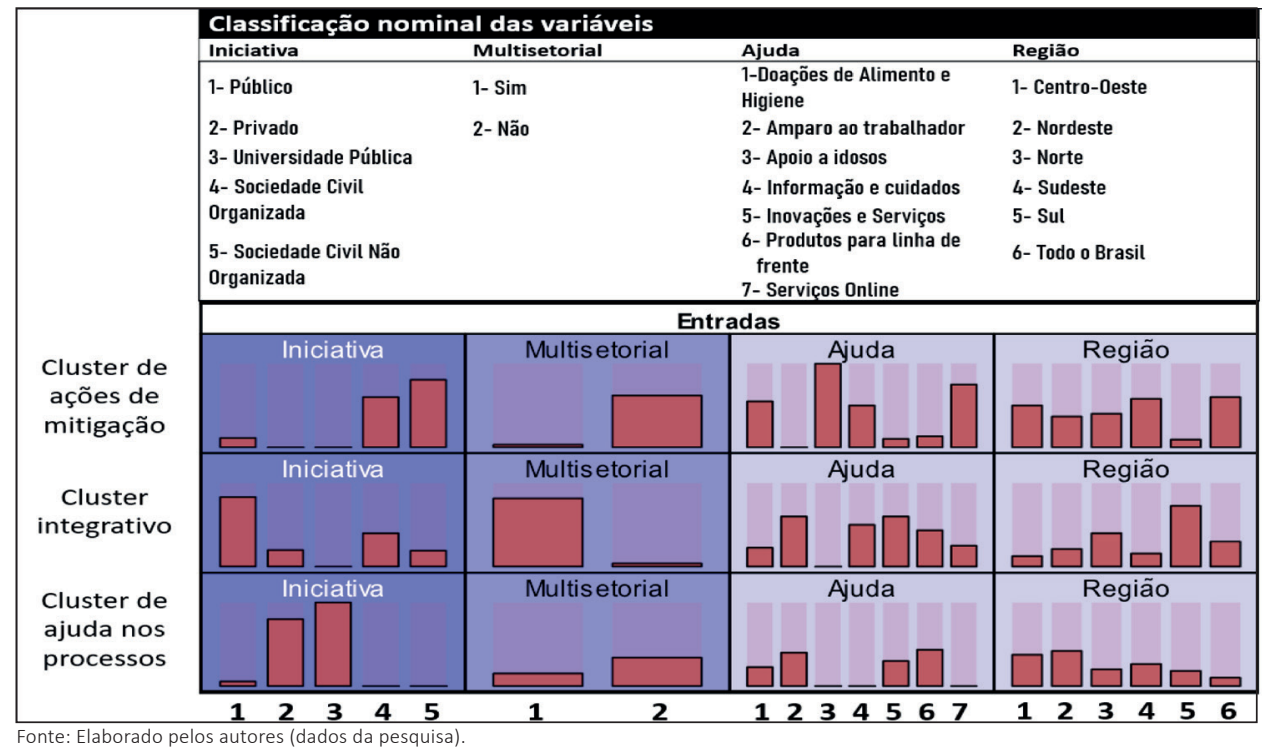

público. Correspondem a 34\% das ações não integradas e 15,2\% das ações multissetoriais. Dentre os tipos de ajuda encontram-se as ações de $43,5 \%$ produtos de linha de frente, $40 \%$ de amparo ao trabalhador, $30 \%$ de inovação e serviço e $22,6 \%$ de doação de alimentos e higiene. Dentre as ações regionais destacaram-se 42,1\% no Nordeste, 37,5\% Centro-Oeste e $26,3 \%$ Sudeste. Neste grupo, a ajuda de apoio a idosos, informações e cuidados e serviços on-line não ocorreram. As notícias de redes de solidariedade desse tipo se destacaram com as iniciativas de universidades públicas e empresas privadas que focaram seus esforços em ajudar no processo de combate à pandemia e seus efeitos. Dentre as notícias desse tipo, observa-se a arrecadação de materiais para fazer máscaras, empresas que mudaram seu sistema de fabricação para produzir álcool em gel para profissionais de saúde, um métodos desenvolvido pela universidade para transformar materiais recicláveis em sabão para os hospitais, empresas que fizeram ação de amparo a trabalhadores desempregados para dedicar-se à fabricação de materiais para a linha de frente do combate a pandemia, entre outros.

A Figura 4 permite observar as características de cada um dos clusters, sua atuação para atender uma diversidade de demandas sociais e sua notável complementaridade. Verifica-se que o cluster de ações de mitigação se destaca pelo apoio a idosos, 
que é justamente o tipo de ação em que o cluster integrativo, preponderantemente de iniciativa pública, está ausente. Destaca-se ainda pela oferta de serviços on-line, lacuna deixada mais evidentemente pelo cluster de ajuda nos processos, que condensa universidades e empresas privadas. Ademais, nas regiões onde o cluster integrativo iniciado no setor público é menos presente, o cluster representado pela sociedade civil se faz mais presente. A verificação da complementaridade nos tipos de ajuda, regiões e articulações multissetoriais aponta que na situação pandêmica, a sociedade civil se organizou em torno das causas que atores como o Estado e o interesse privado estão omissos.

Infere-se desta situação o ciclo da dádiva (dar-receber-retribuir) operando nas iniciativas estudadas. Mauss (2003) explicita que indivíduos mobilizados pela dádiva se sentem obrigados a retribuir, revelando uma percepção de pertencimento a uma realidade social mais ampla, o que o leva a querer garantir as possibilidades materiais para outros grupos aos quais não necessariamente pertence, e a pandemia pode ter sido um gatilho para maior evidenciação desse ciclo. Por outro lado, a análise dos conteúdos das publicações revela que a solidariedade identificada é de maneira mais acentuada a caridade pura, pois não abrange o potencial democrático, pautado na possibilidade de reciprocidade, participação e transformação social.

As iniciativas são emergenciais e pontuais, não tendo se tornado - ainda - movimentos organizados da sociedade civil. A gestão pública e o Estado podem fomentar esse processo de desenvolvimento das redes de solidariedade. Outra questão central identificada por autores da teoria da dádiva (Mauss, 2003; Laville, 2009) é que ela pode promover relações de poder em um ciclo dadivoso em que a retribuição é impossível, o que impulsiona a reflexão sobre as redes solidárias iniciadas por empresas privadas estarem possivelmente interessadas em benefícios econômicos futuros, numa dinâmica de competição por consumidores e fortalecimento da marca.

Em outra vertente, embora o Estado Democrático de Direito tenha o papel de garantir o respeito às liberdades civis, o respeito aos direitos humanos e às garantias fundamentais, a estrutura social, econômica, política e intelectual no Brasil vêm reproduzindo ao longo de séculos situações de pobreza extrema e de desigualdade (Martins, 2004; Brito, 2007). Fica evidente que, com a ausência do Estado, suas responsabilidades de garantia de direitos aos cidadãos são transferidas compulsoriamente (Dagnino, 2004) para os grupos sociais que, mobilizados pela dádiva, tomam a iniciativa de resolver os problemas gerados pela pandemia. A omissão do Estado para equacionar urgentes problemas sociais como a fome, a saúde, a moradia e a educação básica gera um vácuo de ações que passa a ser ocupado por outros atores sociais (Fischer, 1998), caracterizando a diversidade de iniciativas, articulações 
e formas organizativas inovadoras, com as redes solidárias aqui analisadas.

Contudo, em que pese a obrigação do Estado em prover as necessidades da população, identifica-se uma lacuna entre o que deveria ser feito e as ações efetivamente implementadas, e o contexto da pandemia refletiu esse problema, pois o cenário exigiu rápida ação governamental, no sentido de implementação de um orçamento específico para atender às políticas públicas nas áreas social e de saúde, mas que não fossem violados os preceitos normativos atinentes às contas públicas, abrindo, assim, a possibilidade para a execução excepcional de despesas.

Nesse cenário, em 20 de março de 2020, o Poder Legislativo reconheceu a ocorrência de estado de calamidade pública, por meio do Decreto Legislativo n. 6/2020 (Senado Federal, 2020a). Por sua vez, o Supremo Tribunal Federal, em 29 de março de 2020, autorizou o excepcional afastamento, durante o estado de calamidade pública, da incidência de dispositivos contidos na Lei de Responsabilidade Fiscal (LRF) e na Lei de Diretrizes Orçamentárias (LDO) do corrente ano, para fins exclusivos de combate à pandemia de Covid-19 (STF, 2020). Em 7 de maio de 2020, o Poder Legislativo promulgou a Emenda Constitucional do Orçamento de Guerra, a PEC 10/2020 (Senado Federal, 2020b), além da aprovação da Lei Complementar n. 173/2020, que estabeleceu o Programa Federativo de Enfrentamento ao Coronavírus SARS-CoV-2 (Câmara dos Deputados, 2020).

A finalidade desses atos, com a mobilização dos dois poderes da República, foi dar segurança jurídica e ferramentas legislativas para a implementação de políticas públicas emergenciais, com execução a cargo do Poder Executivo. Sua utilidade prática visava o pronto atendimento às necessidades da população, porém, não foi possível perceber a mesma capacidade de mobilização por parte do Executivo Federal. Conforme relatado por Caponi (2020), foi adotada uma postura negacionista de enfrentamento e, em seguida, nesse momento inicial, a linha neoliberal - com os comportamentos que Calmon (2020: 6) chama de "racismo travestido de burocracia" para justificar a morosidade e a clara omissão do Estado na assistência emergencial à população mais vulnerável.

\section{Considerações finais}

O artigo apresentou a primeira resposta em ações solidárias da crise Covid-19 no Brasil. Para tanto, foi realizada uma busca de notícias sobre a formação de redes de solidariedade frente à situação pandêmica no país e realizada uma análise de clusters, em uma discussão baseada na Teoria da dádiva (Mauss, 2003). Como resultado, a primeira resposta à crise sanitária se configurou em três clusters de atores sociais: a sociedade civil agregada no cluster de ações de mitigação; o setor público reunido 
no cluster integrativo; e as universidades e empresas privadas reunidas no cluster de ajuda nos processos. Esta diversidade de clusters revela que a dádiva não é uma dinâmica restrita às organizações cujos objetivos são solidários, mas está incrustada em diferentes setores organizacionais. Esse achado de pesquisa pode estar evidenciando o caráter altruísta que pode mobilizar indivíduos em suas diferentes esferas de atuação, mesmo que tal atuação (organizacional ou individual) não seja prioritariamente a ação solidária, como no caso das universidades ou do setor público no Brasil.

A reflexão que emerge é que essas iniciativas estudadas, por serem espontâneas e com importante capilaridade, impulsionadas pela condição emergencial, fazem com que produtos e serviços cheguem aos públicos demandantes que as iniciativas públicas e do terceiro setor não conseguem atingir rapidamente. Como o fenômeno descrito é o de primeira resposta à crise, momento em que muitas iniciativas solidárias ainda não estavam institucionalizadas, é reforçado o entendimento de que a ética da dádiva tenha sido o fator mobilizador da primeira resposta à crise: dar sem a obrigatoriedade de uma contrapartida imediata e, ao mesmo tempo, como retribuição por uma condição existencial que já foi recebida anteriormente. $A$ primeira resposta espontânea, pouco estruturada e dadivosa, que supre as lacunas deixadas pelo Estado, mais à frente se desenvolveu para modelos mais estruturados de mobilização de doações como aplicativos, sites institucionais e campanhas empresariais. Por outro lado, fica evidenciada a perversidade dessa relação entre Estado e sociedade civil na qual, na medida em que o Estado se isenta de suas obrigações e as transfere para outros atores, isso possa ser conveniente a uma redução proposital de sua esfera de atuação e responsabilidade.

Cabe destacar que o presente estudo capturou e descreveu as características da primeira resposta à crise, identificando seus fundamentos nas relações de dádiva, não sugerindo, no entanto, que o Estado possa se fazer omisso em seu papel constitucional, visto que a sociedade civil venha a se organizar para suprir suas lacunas de atuação. Ao contrário, a captura das esferas de atuação em primeira resposta revela justamente os aspectos e características das lacunas de atuação do Estado, para que este possa estabelecer processos de planejamento nessas vertentes, junto aos demais atores governamentais e sociais, frente a novas situações de crise. Essa conclusão dialoga com o estudo de Schmidt, Mello e Cavalcante (2020), evidenciando a necessidade de uma atuação intersetorial capaz de reunir um extenso rol de atores sociais e mecanismos eficientes de coordenação governamental.

Pelas análises realizadas, foi possível observar que a primeira resposta se configura em rápida mobilização da sociedade civil, ainda que de maneira espontânea e pouco estruturada, para doar produtos e serviços de maneira a complementar 
as lacunas deixadas pelo Estado, o que revela o sentimento de pertencimento a uma coletividade mais ampla, que deve ser zelada por todos por meio de processos semelhantes aos da dádiva. Transcorrido mais tempo, foram criados aplicativos e sites para ordenar a distribuição de doações, ou seja, tais iniciativas ocorreram em um momento posterior como tentativa de organização das doações. As ações envoltas de empatia e solidariedade, que surgiram nesse momento crítico inicial de pandemia do Covid-19, mostram que o ser humano pode ser movido por sentimentos altruístas e que em algum momento isso poderia transportar-se do âmbito individual para o coletivo, ou seja, não ser apenas uma pessoa solidária, mas sim uma sociedade solidária.

Ao considerar que a ideia da solidariedade converge com uma sociedade pluralista e com a própria concepção de cidadania (Reis, 2009; McGoey, 2018), a pandemia pode representar uma oportunidade ímpar para que a população brasileira repense as formas de consumo, as estruturas sociais desiguais, as políticas econômicas e como a gestão pública pode gerir, de modo mais eficiente, situações de crise. Espera-se, sobretudo, que lições sejam aprendidas e que sejam buscados novos caminhos baseados na inovação social, economia solidária, cooperativa popular, desenvolvimento local e sustentabilidade, todas essas perspectivas ensejadas pela sociologia da dádiva.

Além disso, as análises realizadas permitem vislumbrar uma melhor atuação para a administração pública em três grandes eixos: legitimidade e reconhecimento das redes solidárias; fomento da parceria público-privada; e investimento para a ciência e tecnologia. Observa-se o potencial das redes formadas pela sociedade civil em contribuir com a capilaridade de políticas públicas destinadas às classes sociais vulneráveis. Percebe-se que, devido a sua atuação direta com a população, a sociedade civil pode ser um veículo de concretização dessas políticas, desde que o Estado não se exima de suas obrigações. Sugere-se que o governo crie plataformas institucionais, seja por meio de um site ou de um aplicativo, para mapear e cadastrar as redes de solidariedade, o que pode gerar legitimidade e reconhecimento para esses atores, facilitando as ações descentralizadas. Adicionalmente, o Estado pode ter acesso aos dados sobre essas necessidades locais, o que pode contribuir para a efetividade das políticas públicas.

A iniciativa privada desempenha um papel importante na crise Covid-19, uma vez que as doações representam disponibilidade de recursos financeiros e de serviços frente à pandemia. Considerando a responsabilidade social corporativa e o potencial das parcerias público-privada, espera-se que novos modelos de colaboração, com a transparência e a responsabilidade necessárias, sejam formados a partir da 
complementaridade de conhecimentos e recursos, até mesmo junto às instituições de ensino e pesquisa, visando uma gestão integrativa e multissetorial não ancorada apenas na caridade.

Ademais, as análises mostraram o potencial das universidades públicas como ente propulsor de inovação em produtos de prevenção, proteção e cuidados no combate à pandemia, bem como agente facilitador na conscientização da população. A crise global Covid-19 se torna um momento propício para os governos repensarem suas políticas de investimento em pesquisa e desenvolvimento, pois, como pilar do crescimento econômico e social do país, a educação deve ser prioridade, pois fortalece os processos democráticos.

A crise atual evidenciou a necessidade de parcerias entre diversos setores. A administração pública tem competência, responsabilidade e recursos suficientes para aperfeiçoar mecanismos de logística, coordenação e transparência dessas redes de solidariedade. Espera-se uma atuação governamental articulada e capaz de coordenar os esforços dos atores sociais, o que pode representar agilidade e efetividade em diversas políticas públicas. Novas crises sanitárias poderão surgir exigindo organização e planejamento para enfrentar estes complexos desafios.

De modo não exaustivo, admitem-se limitações no artigo: o uso apenas das notícias veiculadas, não recorrendo a outras fontes, restringiu as informações das redes de forma abrangente. Por outro lado, buscou-se avançar no campo teórico trazendo a Teoria da dádiva para explicar as redes solidárias, bem como implicações do ponto de vista prático, propondo uma agenda de atuação para a administração pública. Além disso, podem ser realizados estudos específicos a partir dos clusters identificados: ações de mitigação; cluster integrativo e cluster de ajuda nos processos. As diferenças regionais identificadas entre os clusters podem ser objeto de investigação, ou seja, como fatores institucionais, sociais ou culturais das regiões podem influenciar a forma de articulação entre o Estado, as organizações e a sociedade civil? Além disso, estudos futuros podem ampliar as bases de dados, inclusive para análise de redes sociais virtuais, bem como podem realizar uma análise longitudinal dos clusters conforme os números de casos de Covid-19 avançarem no país.

Por fim, espera-se que a crise da Covid-19 se transforme em oportunidade para o Estado alavancar soluções inovadoras, compreender melhor as necessidades dos setores e repensar políticas públicas. As redes de solidariedade podem se tornar um meio legítimo de o governo descentralizar ações e chegar aos indivíduos invisibilizados. As barreiras geográficas finalmente podem ser transpostas pela tecnologia, não seria o momento de se formar redes solidárias internacionais? Em meio 
a complexos desafios globais impostos pela pandemia, grandes lições podem ser aprendidas, entre a dádiva, a cooperação e o compromisso mútuo, vislumbram-se diversas possibilidades para uma gestão pública efetiva e uma sociedade solidária e democrática.

\section{Referências}

AGUIAR, V. Os argonautas da internet: uma análise netnográfica sobre a comunidade on-line de software livre do projeto Gnome à luz da teoria da dádiva. Dissertação (Mestrado) - Escola de Administração da Universidade Federal da Bahia, Salvador, Bahia, 2007.

BREIGER, R. L; ROBERTS, J. M. Solidarity and social networks. In: DOREIAN, Patrick; FARARO, Thomas. The problem of solidarity: theories and models, p. 239-262. Abingdon, UK: Taylor and Francis Inc., 2012.

BRITO, P. Redes, solidariedade e cidadania democrática: a experiência inovadora da articulação do semiárido (ASA). Tese (Doutorado) - Centro de Filosofia e Ciências Humanas, Universidade Federal de Pernambuco, Recife, Pernambuco, 2007.

BURKOWSKI, R.; BOAS, A. A. V. Dádiva na gestão de unidades de conservação: um estudo sobre a participação de conselheiros do mosaico Veredas-Peruaçu, Brasil. Administração Pública e Gestão Social, v. 5, n. 4, p.168-174, 2013. Disponível em: <https://doi.org/10.21118/apgs.v5i4.524>. Acessado em: 12 Maio 2020.

CAILLÉ, A. Antropologia do dom: o terceiro paradigma. Petrópolis, RJ: Vozes, 2002.

CALMON, T. V. L. As condições objetivas para o enfrentamento ao Covid-19: abismo social brasileiro, o racismo, e as perspectivas de desenvolvimento social como determinantes. NAU Social, v. 11, n. 20, p. 131, 2020.

CÂMARA DOS DEPUTADOS. Lei Complementar n. 173, de 27 de Maio de 2020. Disponível em: <https://www2.camara.leg.br/legin/fed/leicom/2020/leicomplementar-173-27-maio-2020-790237-norma-pl.html>. Acesso em: 18 Out. 2020.

CAPONI, S. Covid-19 no Brasil: entre o negacionismo e a razão neoliberal. Estudos Avançados, v. 34, n. 99, p. 209-224, 2020.

CLARKE, J. Solidarity and survival: a multidisciplinary exploration of volunteering during the Greek crisis, In: J. CLARKE et al. (Eds.) Austerity and the third sector in Greece: civil society at the European frontline, p. 67-84. London: Ashgate, 2015. 
COHRS, F. M.; SOUSA, F. S.; TENÓRIO, J. M.; RAMOS, L. R.; PISA, I. T. Aplicação de Análise de Cluster em dados integrados de um estudo prospectivo: projeto epidoso como cenário. Journal of Health Informatics, v. 5, n. 1, p. 17-22, 2013.

DAGNINO, E. Sociedade civil, participação e cidadania: de que estamos falando? In: MATO, D. (Org.). Políticas de ciudadanía y sociedad civil en tiempos de globalización. Caracas: Universidad Nacional de Venezuela, 2004.

Os movimentos sociais e a emergência de uma nova noção de cidadania. Anos 90 - política e sociedade no Brasil. São Paulo: Brasiliense, 1994.

DAGNINO, E., OLVERA, A., PANFICHI, A., Introducción: Para otra lectura de la disputa por la construcción democrática en América Latina. In: DAGNINO, E.; OLVERA, A.; PANFICHI, A. (Orgs.). La disputa por la construcción democrática en América Latina. México: Fondo de Cultura Económica; Centro de Investigaciones y Estudios Superiores en Antropología Social; Universidad Veracruzana, 2006.

FISCHER, R. Non-governments: NGOs and the political development of the third world. West Hartford, CT: Kumarian, 1998.

FÓRUM SOCIAL MUNDIAL (FSM). Relatório de atividades do encontro anual 2016. Disponível em: <https://fsm2016.org/wp-content/uploads/2017/01/RAPPORT_ FSM2016_anglais.pdf>.

FRANÇA FILHO, G. C. de. A problemática da economia solidária: um novo modo de gestão pública? Cadernos Ebape. P. 443-461, 2013. Disponível em: <http://bibliotecadigital.fgv.br/ojs/index.php/cadernosebape/article/view/11653>. Acessado em: 12 Maio 2020.

GADELHA, T. S. M. Teoria da dádiva e empresa familiar - limites, possibilidades e desafios analíticos: um estudo de caso no setor de transporte coletivo do município de Salvador. Dissertação (Mestrado) - Escola de Administração da Universidade Federal da Bahia, Salvador, Bahia, 2007.

GARGIULO, M; BENASSI. Preso em sua própria rede? Coesão de redes, buracos estruturais e adaptação do capital social. Organization Science, v. 11, n. 2, p.183-196, 2000 .

GEORGEOU, N; HAAS, B. Power, exchange and solidarity: case studies in youth volunteering for development. Voluntas - International Journal of Voluntary and Nonprofit Organizations, v. 30, n. 6, p. 1406-1419, 2019.

GIACOMONI, J. Orçamento público. 15 ed. São Paulo: Atlas, 2010. 
GODELIER, M. O enigma do Dom. Rio de Janeiro: Civilização Brasileira, 2001.

GODOY, A. S. Pesquisa qualitativa: tipos fundamentais. Revista de Administração de Empresas, v. 35, n. 3, p. 20-29, 1995.

GONÇALVES, A. F. A história dos fundos rotativos solidários no estado da Paraíba: a construção político-institucional de uma política pública. Revista Gestão Pública, "Práticas e desafios I", p.225-241, 2010.

GUADALUPE, S; CARDOSO, J. As redes de suporte social informal como fontes de provisão social em Portugal: o caso da população idosa. Sociedade e Estado, v. 33, n. 1, p. 213-248, 2018.

HAIR, J. F.; BLACK, W. C.; BABIN, B. J.; ANDERSON, R. E.; TATHAM, R. L. Análise multivariada de dados. Porto Alegre, RS: Bookman Editora, 2009.

LACERDA, A; MARTINS, P. H. A dádiva no trabalho dos agentes comunitários de saúde: a experiência do reconhecimento do amor, do direito e da solidariedade. Realis - Revista de Estudos Anti-Utilitaristas e Pós-Coloniais, v. 3, p. 194-213, 2013.

LAVILLE, J.-L. A economia solidária: Um movimento internacional. Revista Crítica de Ciências Sociais, n. 84, p.7-47, 2009. Disponível em: <https://doi.org/10.4000/ rccs.381>. Acessado em: 16 Maio 2020.

MALLARD, G. The gift revisited: Marcel Mauss on war, debt, and the politics of reparations. Sociological Theory, v. 29, n. 4, p. 225-247, 2011. Disponível em: <https:// doi.org/10.1111/j.1467-9558.2011.01398.x>. Acessado em: 13 Maio 2020.

MARTINS, P. H. A sociologia de Marcel Mauss: Dádiva, simbolismo e associação. Revista Crítica de Ciências Sociais, n. 73, p. 45-66, 2005.

Gestão pública, reciprocidade e obrigação redistributivista: uma agenda para a reforma moral do Estado. Revista Tomo, n. 7, 2004.

MAUSS, M. Ensaio sobre a dádiva. In: MAUSS, M. Sociologia e antropologia. São Paulo: Cosac \& Naif, 2003.

MCGOEY, L. Bataille and the sociology of abundance: reassessing gifts, debt and economic excess. Theory, Culture \& Society, v. 35, n. 4-5, p. 69-91, 2018.

MELUCCI, A. A invenção do presente. Movimentos sociais nas sociedades complexas. Petrópolis, RJ: Vozes, 2001.

MULLAN , C.; COX , L. Movimentos sociais nunca morreram: políticas comunitárias e economia social na República da Irlanda. Paper presented at the symposium 
"Os movimentos sociais estão revivendo?" Manchester, UK: Manchester University, 2000.

NEAMTAN, N. The social and solidarity economy: towards an "alternative" globalization. Paper presented at the symposium "Citizenship and globalization: exploring participation and democracy in a global context". Vancouver, CA: Langara College, Jun. 2002.

REIS, F. W. Desigualdade, identidade e cidadania. Sociedade e Cultura, v. 12, n. 1, p. 117-126, 2009.

RIGO, A. S; FRANÇA FILHO, G. C. O paradoxo das Palmas: análise do (de)uso da moeda social no "bairro da economia solidária". Cadernos Ebape. v. 15, n. 1, p. 169-193, 2017.

SABOURIN, E. Dádiva e reciprocidade nas sociedades rurais contemporâneas. Tomo, Revista de Ciências Sociais, n. 7, p. 75-104, 2004.

SCHMIDT, F.; MELLO, J.; CAVALCANTE, P. Estratégias de coordenação governamental na crise da Covid-19. Nota Técnica n. 32. Brasília: Instituto de Pesquisa Econômica Aplicada (Ipea), 2020.

SENADO FEDERAL. "Em sessão histórica, Senado aprova calamidade pública contra covid-19", 2020a. Disponível em: <https://www12.senado.leg.br/noticias/materias/2020/03/20/em-sessao-historica-senado-aprova-calamidade-publica-contra-covid-19>. Acesso em: 14 Set. 2020.

PEC 10/2020, institui regime extraordinário fiscal, financeiro e de contratações para enfrentamento da calamidade pública nacional decorrente de pandemia internacional. Brasília: Senado Federal, 2020b.

SILVA, M. C.; SILVA, K.; SIQUEIRA, L. A. R.; ANDRADE, M. A. C. Acontecimento COVID-19: e daí? Scielo Preprints. 2020. Disponível em: <https://preprints.scielo.org/ index.php/scielo/preprint/view/520>. Acessado em: 07 Jun. 2020.

SMITH, J. Solidarity networks: what are they? And why should we care? The Learning Organization, v. 16, n. 6, p. 460-468, 2009.

SUPREMO TRIBUNAL FEDERAL (STF). ADI 6357, "Plenário referenda cautelar que afastou restrições da LRF e da LDO para combate à pandemia". Brasília: STF, 2020.

TACKACS , K.; JANKY , B.; FLACHE , A. Ação coletiva e mudança de rede, Paper presented at the symposium MKE 2007, Budapest, 2007. 
TENÓRIO, F. Um espectro ronda o terceiro setor: o espectro do mercado. Revista de Administração Pública (RAP), Rio de Janeiro, v. 5, p. 85-102, 1999.

VIZEU, F. Contribuições da sociologia da dádiva aos estudos sobre organizações substantivas. Organizações \& Sociedade, v. 16, n. 50, p. 409-427, 2009.

WATERMAN, P. The global justice and solidarity movement and the World Social Forum: A backgrounder. In: World Social Forum: Challenging Empires, p. 55-66, 2004.

WEI, J; MARINOVA, D. The orientation of disaster donations: differences in the global response to five major earthquakes. Disasters, v. 40, n. 3, p. 452-475, 2016. 